\title{
Analysis of intracranial aneurysms treated at a University Hospital in Curitiba
}

\author{
Johnni Oswaldo Zamponi Junior ${ }^{1}$, Paulo Eduardo Carneiro da Silva², \\ Guilherme Zandavalli Ramos ${ }^{1}$, Guilherme Mailio Buchaim ${ }^{1}$, \\ Lucas Cunha de Andrade ${ }^{1}$, Luis Fernando Macente Sala ${ }^{1}$
}

Hospital Universitário Evangélico de Curitiba, PR.

\begin{abstract}
Objective: The aim of this paper is analyze the population and the types of intracranial aneurysms treated in the neurosurgery service of the Hospital Universitário Evangélico of Curitiba (HUEC), checking possible relations of this pathology with some risk factors and analyzing also the result of the treatment of this patients. Method: We reviewed the hospital files, surgical and out-patient notes of all patients operated on for the treatment of intracranial aneurysms from January 2006 to December 2010, composing a sample of 93 patients. The variables analyzed were gender, age, history of hypertension, smoking habit, diabetes mellitus, site of aneurysm, score scales Hunt-Hess and Fisher at hospital admission and treatment outcome of aneurysms using the Glasgow Outcome Scale (GOS). Results: The patients studied were predominantly women (73\%), ranging in age from 51 to 60 years (38\%), with a history of hypertension (61\%). At admission, the grade 1 in a Hunt-Hess scale was most frequent (31\%), while grade 4 on a scale of Fisher was more prevalent (26\%). Aneurysms were more frequent in the anterior circulation, mainly affecting the middle cerebral artery. The most frequent score in GOS was 5 (40\%). Conclusion: Subarachnoid hemorrhage is an event that may worsen the outcome of treatment of patients with intracranial aneurysms, so there is a correlation between the amount of bleeding identified on CT and prognostic evolution.
\end{abstract}

\section{KEYWORDS}

Intracranial aneurysms/classification, intracranial aneurysms/complications, risk factors, outcome and process assessment (health care), retrospective studies.

\section{RESUMO}

Análise dos aneurismas intracranianos tratados em um Hospital Universitário de Curitiba Objetivo: O objetivo deste trabalho é analisar a população e os tipos de aneurismas intracranianos tratados no serviço de neurocirurgia do Hospital Universitário Evangélico de Curitiba (HUEC), verificando possiveis relações dessa patologia com alguns fatores de risco e analisando também o resultado do tratamento desses pacientes. Método: Foram revistos os prontuários e descrições de cirurgia de todos os pacientes operados para tratamento de aneurismas intracranianos no período de janeiro de 2006 a dezembro de 2010, compondo uma amostra de 93 pacientes. As variáveis avaliadas foram gênero, idade, história de hipertensão arterial sistêmica, tabagismo, diabetes mellitus, local do aneurisma, pontuação das escalas de Hunt-Hess e Fisher na admissão hospitalar e o resultado do tratamento dos aneurismas utilizando a Escala de Prognóstico de Glasgow (GOS). Resultados: Os pacientes estudados foram predominantemente mulheres (73\%), na faixa etária entre 51 e 60 anos (38\%), com história de hipertensão (61\%). À admissão hospitalar, o grau 1 na escala de Hunt-Hess foi mais frequente (31\%), enquanto o grau 4 na escala de Fisher foi mais prevalente (26\%). Aneurismas mais frequentes foram na circulação anterior, acometendo principalmente a artéria cerebral média. A pontuação na escala de GOS mais frequente foi 5 (40\%). Conclusão: A hemorragia subaracnoide é um evento que pode piorar o resultado do tratamento de pacientes com aneurismas intracranianos, havendo, assim, uma correlação entre o volume de sangramento identificado na tomografia e a evolução prognóstica.

\section{PALAVRAS-CHAVE}

Aneurismas intracranianos/classificação, aneurismas intracranianos/complicações, fatores de risco, avaliação de processos e resultados (cuidados de saúde), estudos retrospectivos. 


\section{Introduction}

Intracranial aneurysms are classified as saccular, fusiform and dissecting. Approximately 90\% are saccular dilatations appearing as rounded or lobulated and protrusions that usually originate in the arterial bifurcations. It is generally considered acquired lesions resulting from prolonged hemodynamic stress and subsequent degeneration at the level of local bifurcations and arterial branching. Regarding the size, intracranial aneurysms are divided according to their angiographic appearance, in: small (up to $12 \mathrm{~mm}$ ), large (between 12 and $25 \mathrm{~mm}$ ) and giant (greater than $25 \mathrm{~mm}){ }^{1}$

The true incidence of cerebral aneurysms is unknown, but it is estimated that these arterial dilations occur between $1 \%-6 \%$ of the population. ${ }^{2}$ It can occur multiple aneurysms, which are found around $20 \%$ of cases with a predominance in the female population.

Most aneurysms are asymptomatic and are diagnosed only after the break, which is a crucial aspect in the natural history of them. Ruptured aneurysms can not be found incidentally during the course of radiological investigation for other pathologies. Subarachnoid hemorrhage $(\mathrm{SAH})$ is the most common initial manifestation of ruptured aneurysms, and is considered a medical emergency, with high rates of morbidity and mortality when present. It is typically expressed by headache, neck stiffness and altered level of consciousness, with headache as the most common symptom, present in up to $97 \%$ of cases, which is referred to by patients as the worst headache of your life. When there is a ruptured cerebral aneurysm is a sharp rise in intracranial pressure, with levels of systolic blood pressure, this result in a decrease in cerebral perfusion pressure, resulting in a high reduction of cerebral blood flow. Rupture of an aneurysm can also cause bleeding within the brain parenchyma, ventricular system and even the subdural space and may cause the formation of an acute hydrocephalus due to changes in cerebrospinal fluid circulation, which may worsen the patient's condition. ${ }^{3}$

Approximately one third of patients with ruptured aneurysms die before receiving medical care levels and mortality reaches $50 \%$ among the remaining patients. The incidence of subarachnoid hemorrhage due to rupture of aneurysms is estimated between 6 to 10 per 100,000 individuals. ${ }^{4,5}$ Irregular multilobulated aneurysms are more prone to breakage.

Kassel and Drake ${ }^{6}$ revealed that a total of 28,000 ruptured aneurysms in North America, 18,000 survived the first episode, and of these only 9,000 fully resumed their previous activities, being only $40 \%$ returned to functional life despite modern treatment techniques.

Suzuki et al. ${ }^{7}$ ruled that the rupture usually takes place between the ages of 40 and 60 years, with peak incidence in the fifth decade, occurring rarely during childhood and adolescence. The rupture rate gradually increases until the sixth decade, when it reaches its peak and tends to decline to low levels after the eighth decade of life.

Besides the large number of patients with ruptured aneurysms, neurosurgeons frequently encounter patients who develop neurological deficits by mass effect due to the growth of intracranial aneurysms, or compression of cranial nerves or even focal cerebral ischemic symptoms related to embolization distal from thrombosed aneurysms, which occur mainly in large and giant aneurysms.

Regarding the etiology of this lesion, the literature shows that it is due to factors resulting from the association of congenital histological, hemodynamic, and degenerative diseases. Krex et al. ${ }^{8}$ found that several congenital factors were implicated in the pathogenesis of these lesions, such as defects in the media and elastic lamina, since the cerebral arteries lack external elastic lamina and intimal and medial layers are thinner. Associated with this is the fact that the level of bifurcation of cerebral arteries there is less resistance to hemodynamic factors, since this level there will break in continuity of the middle layer, which allows direct contact between this layer and the adventitia, which with prolonged stress can cause a focal degeneration of internal elastic lamina favoring the formation of saccular aneurysms. This author also ruled that other factors also influence the synthesis of this injury, among them are: hypertension, diabetes mellitus, dyslipidemia, smoking, use of medications such as anticoagulants, and inherited diseases such as Ehlers-Danlos syndrome, Marfan syndrome, neurofibromatosis type I and II, and autosomal dominant polycystic kidney disease. Infiltration of blood, inflammation and necrosis due to infection may also cause weakness of the arterial wall and consequently aneurysm.

The methods for the evaluation of cerebral aneurysms include magnetic resonance angiography (MRA), CT angiography (CTA), ultrasound and transcranial Doppler angiography with intra-arterial digital subtraction, the latter being considered the gold standard method. ${ }^{9}$

\section{Methods}

It was designed a retrospective study of patients with intracranial aneurysms treated by the Neurosurgical Service of Evangelical Hospital of Curitiba between January 2006 and December 2010, comprising a sample of 93 cases. The variables analyzed were sex, age, history of hypertension, diabetes mellitus, history of 
alcoholism, smoking and aneurysm location. Patients with ruptured aneurysms were scored by Hunt-Hess scale for analysis of clinical conditions, and Fisher, for assessment of radiological evidence, which were measured in the same hospital admission. To analyze the results of treatment of intracranial aneurysms was used in the Glasgow Prognosis Scale (GOS), which was measured by monitoring the same patients over a period of three to six months after hospital discharge, enabling the analysis of the overall prognosis and the degree of disability established them.

\section{Results}

The analysis of the sample of 93 patients brought a significant prevalence of females; 68 people were women, representing $73 \%$ of the amount, and the male had a lower incidence (27\%).

Regarding the age of these patients, the main age group affected was between 51 and 60 , corresponding to approximately $38.7 \%$ of the total, followed by the range between 41 and 50, which corresponded to $24.7 \%$ of the sample. There were no cases under the age of 20 years, and only 2 cases $(2.1 \%)$ of patients 70 years or more (Figure 1).

Regarding the presence of single or multiple aneurysms, 24 patients (26\%) had multiple aneurysms, and $74 \%$ had only one aneurysm. Due to the presence in some cases of multiple aneurysms have been well analyzed a total of 120 intracranial aneurysms.

With that being said about the location of these intracranial expansions, the main blood vessel in the sample affected was the middle cerebral artery (MCA) which was achieved in 44 cases (36.6\%), followed by aneurysms of the internal carotid artery (ICA) occurring in 31 patients $(25.8 \%)$. The arteries were the least affected were anterior cerebral artery (ACA) $(3.3 \%)$ and basilar artery (BA) (2.5\%) (Figure 2).

In evaluating the clinical status of patients at the entrance to the service using a scale of Hunt-Hess, the grade 1 , characterized by a mild headache or a mild neck stiffness or even the asymptomatic patient, which was the most presented, corresponding $31,1 \%$; followed by $26.8 \%$ with grade 2 . The grade 5 , characterized by a deep coma and the dying patient, was present in only 9 cases $(9.6 \%)$ (Figure 3 ).

In relation to the scale of Fisher score, which allowed the measurement of radiologic evidence of prior surgical procedures, the grade 4 , characterized by intraventricular or intracerebral hemorrhage, was the most sentenced corresponding approximately $26.8 \%$. The grade 1 , found in patients with absence of hemorrhage on CT, corresponded approximately $24.7 \%$ of the total (Figure 4 ).

Regarding the prognosis of these patients, a group of 38 people (40.8\%) progressed to a good recovery after surgery, being able to return to their usual activities. The installation of a moderate disability, where the patient is capable of living independently but unable to return to work or school, was observed in 10 cases (10.7\%). The presence of a severe deficiency, characterized by the individual who is able to follow commands but can not live independently, was sentenced in 13 patients (13.9\%). Already a sample of 30 persons (32.2\%) died, and in only 2 cases $(2.1 \%)$ there was an evolution to a permanent vegetative state.

In the analysis of risk factors for intracranial aneurysms, a total of $61.2 \%$ of cases had a history of hypertension, and $15 \%$ had the habit of smoking. Other factors were less sentenced, as the presence of diabetes mellitus, present in $10 \%$ of the sample, and alcoholism, as evidenced in $4.3 \%$ of cases.

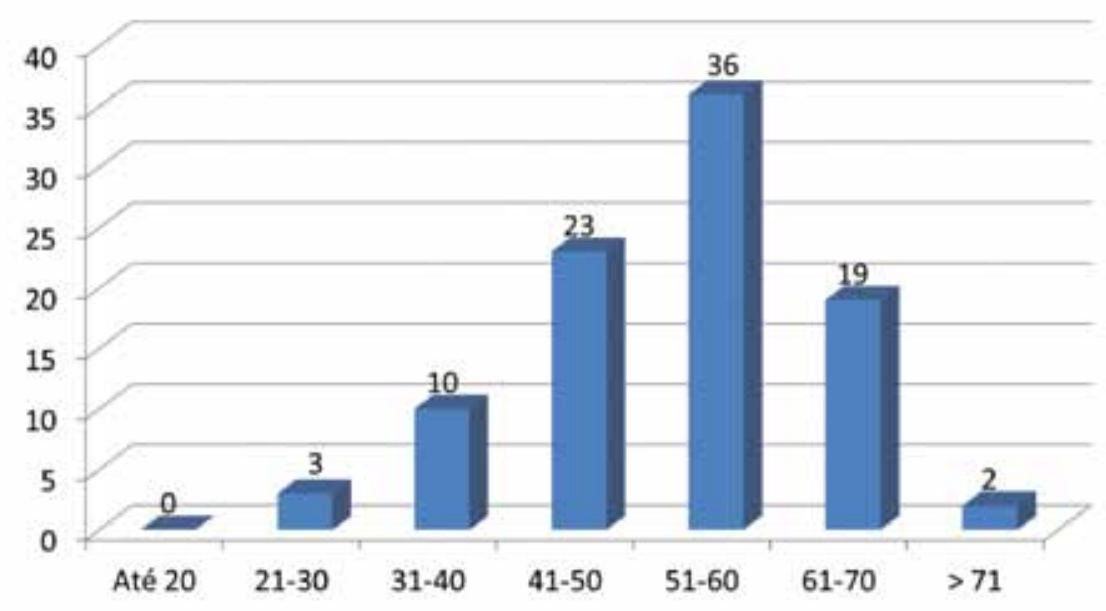

Figure 1 - Age of 93 cases reviewed. 


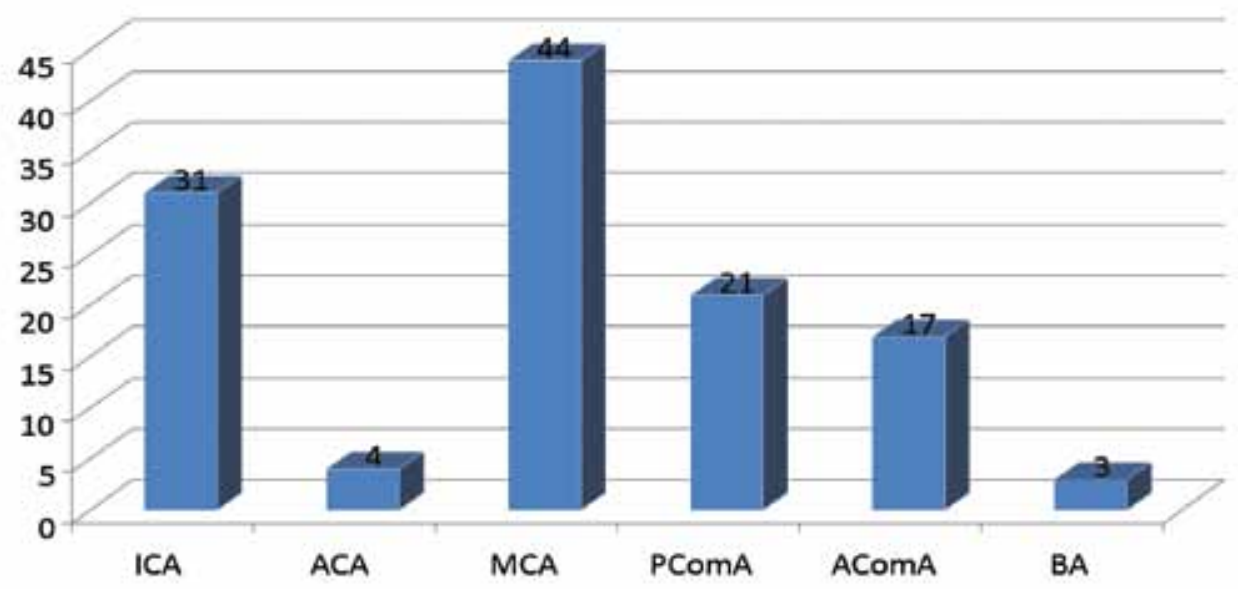

Figure 2 - Location of intracranial aneurysm.

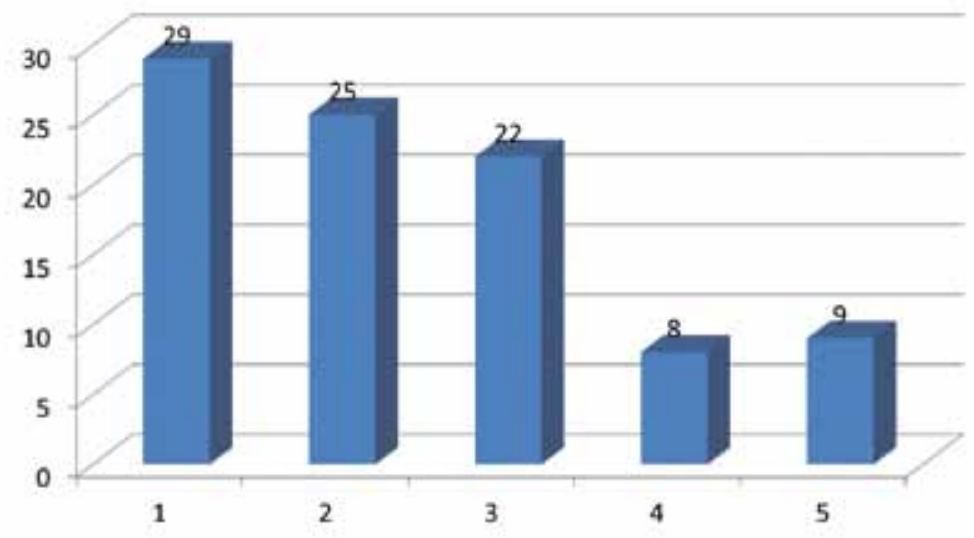

Figure 3 - Clinical analysis of patients using a scale of Hunt-Hess.

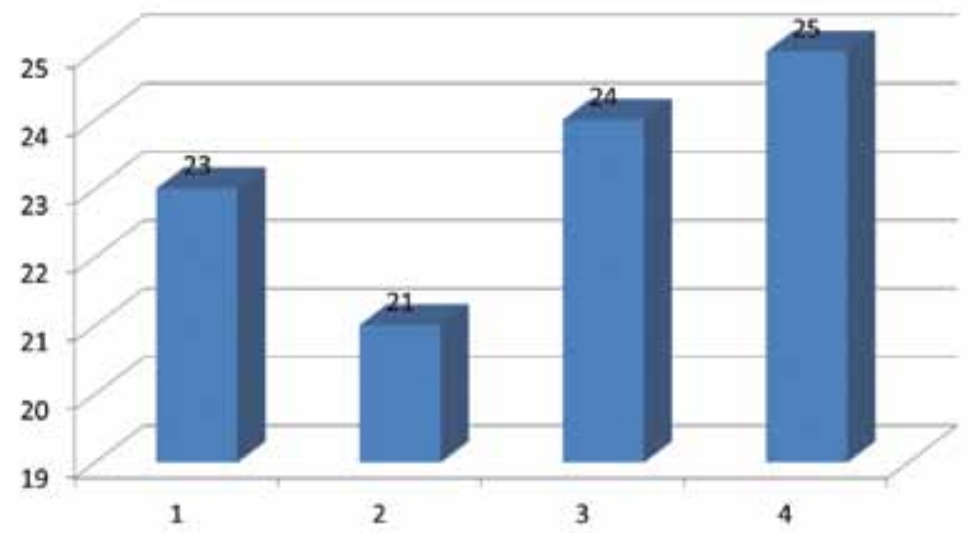

Figure 4 - Radiological analysis of patients through the scale of Fisher. 


\begin{tabular}{|c|c|c|c|c|}
\hline & HUEC (2011) & Lai et al. (2009) & Ishibashi et al. (2009) & Suzuki et al. (1971) \\
\hline Total & 93 & 266 & 419 & 3548 \\
\hline \multicolumn{5}{|l|}{ Sex } \\
\hline Male & $25(27 \%)$ & $89(33 \%)$ & $139(33 \%)$ & $1916(54 \%)$ \\
\hline Female & $68(73 \%)$ & $177(67 \%)$ & $280(67 \%)$ & $1614(46 \%)$ \\
\hline \multicolumn{5}{|l|}{ Aneurysms } \\
\hline Single & $69(74 \%)$ & $222(83 \%)$ & $298(71,1 \%)$ & $3275(92,3 \%)$ \\
\hline Multiple & $24(26 \%)$ & $45(17 \%)$ & $121(28,9 \%)$ & $273(7,7 \%)$ \\
\hline \multicolumn{5}{|c|}{ Localization } \\
\hline ICA & $31(26 \%)$ & $23(8,6 \%)$ & $216(41 \%)$ & $1612(41,3 \%)$ \\
\hline ACA & $4(3 \%)$ & $11(4,1 \%)$ & $107(20 \%)$ & $351(9 \%)$ \\
\hline MCA & $44(37 \%)$ & $40(15 \%)$ & $141(27 \%)$ & $809(20,8 \%)$ \\
\hline AComA & $17(14 \%)$ & $60(22,5 \%)$ & - & $970(24,9 \%)$ \\
\hline PComA & $21(17,5 \%)$ & $70(26 \%)$ & - & - \\
\hline BA & $3(2,5 \%)$ & $15(5,6 \%)$ & $65(12 \%)$ & $156(4 \%)$ \\
\hline
\end{tabular}

\section{Discussion}

The data obtained from our survey are very similar to the literature that says about the female be considered a "risk factor" for the formation and growth of cerebral aneurysms, because in our sample $73 \%$ of cases are women, having this predominance after 41 years. One hypothesis for this is based on the fact that with the decrease in plasma levels of sex hormones in post menopausal women, there would be an inhibition of collagen formation, and thus can affect the brain blood vessels. ${ }^{10,11}$

The point prevalence of multiple aneurysms in our series was $26 \%$, falling between the average suggested by the literature, $17 \%$ to $30 \%$. Studies say that the prevalence of multiple aneurysms changes according to the prevalence of risk factors for aneurysm formation in various populations. ${ }^{12,13}$ In our series there was a significant difference in the proportion of multiple aneurysms in men and women, with a high number of cases in females, showing that gender is an important risk factor for the formation of multiple aneurysms.

Among the risk factors studied have to consider mainly hypertension, which is present in $61 \%$ of our patients, which is extremely important for the development, growth and rupture of cerebral aneurysms. Studies on the pathogenesis of atherosclerosis show a high tendency for hypertension to cause injury in the intima of the vessel, due to several factors, such as activation of apoptosis, and coagulation protein degradation, ${ }^{14}$ thus taking a high probability of causing change in wall the vessel, enabling the development of aneurysms. Another important risk factor is smoking, since it is present in $14 \%$ of the sample. However, risk factors such as smoking, alcohol consumption and even atherosclerosis can not explain the development of aneurysms in young patients, which have a high mortality.
Concerning the location and redistribution of intracranial aneurysms, $80 \%$ occurred in the anterior circulation (carotid system) and approximately $20 \%$ was located in the posterior (vertebrobasilar system), this results were very similar to the literature; Suzuki et al. ${ }^{7}$ ruled that about $87 \%$ occur in the anterior circulation and approximately $13 \%$ is located in the posterior region, it having around $95 \%$ of cases located in five major cerebral arteries, which are the internal carotid arteries, the anterior cerebral arteries, the arteries middle cerebral, vertebral arteries and basilar artery.

The middle cerebral artery (MCA) was the principal place of occurrence of cerebral aneurysms in our sample, occurring in $36 \%$ of patients. Other series bring different data, Lai et al. ${ }^{15}$ that analyzed 266 patients with intracranial aneurysms, and ruled that the vessel most commonly affected was the posterior communicating artery, with an incidence of $26 \%$. On the other hand, Ishibashi et al. ${ }^{16}$ and Suzuki et al. ${ }^{7}$ have as intracranial artery most affected internal carotid artery (ICA), both with a percentage of $41 \%$ of the patients (Table 1 ).

The MCA aneurysms have typically a wide neck and its major branches emerge from the base and are housed inside the Silvius's cistern. The bifurcation of the MCA is where it installs $90 \%$ of aneurysms of this artery, being one of the most affected by the atherosclerotic process, thus presenting a worse prognosis in cases of elderly patients.

The second main artery committed in our study was the internal carotid, representing $25 \%$ of intracranial aneurysms. The internal carotid artery aneurysms are mainly located at the point of bifurcation of this artery, because this location has a high hemodynamic stress, which weakens the vessel wall and promotes the formation of aneurysms. Thus, the swirling blood flow in the aneurysmal sac causes degenerative changes that weaken 
the wall of the aneurysm allowing the expansion of this expansion, increasing the possibility of rupture of the same.

Great series sentenced a high mortality and morbidity in stroke patients with intracranial aneurysms with a mortality after 60 days around $50 \%$ and more than a third of victims had a permanent disability, ${ }^{17,18}$ our study has brought a lower mortality, revolving around $32 \%$. In contrast, the International Cooperative Study on the Timing of Aneurysm Surgery, with a sample of 2,922 patients undergoing surgical treatment for ruptured intracranial aneurysms in 68 different centers around the world, reported a mortality of $14 \%, 69 \%$ of victims presenting between GOS 4 and $5 .{ }^{19}$ Osawa et al. ${ }^{20}$ analyzed 2,055 patients treated in Japan, and sentenced a mortality of $12.9 \%$, one of the lowest found in the literature, also showing good results (GOS 4 to 5 ) in $68.5 \%$ of patients.

\section{Conclusion}

Despite the great progress in diagnostic tools, intensive care, and advances in microsurgery and microanatomy, intracranial aneurysms are still a major cause of death and disability in the practice of neurosurgery. Over time, it was possible to develop a reference standard and protocols for an expanded and appropriate management of patients with subarachnoid hemorrhage, thus enabling an optimal treatment for these patients in an attempt to reduce the high morbidity which are related with this pathology.

From the study we can see that our statistics are very similar to the data provided by the literature, showing satisfactory results in terms about the prognosis of patients when compared with other works, and conclude that subarachnoid hemorrhage is an event that can worse treatment outcome of patients with intracranial aneurysms, so there is a correlation between the amount of bleeding identified on CT and prognostic evolution.

\section{References}

1. Greenberg MS. Manual de neurocirurgia. $5^{a}$ ed. Porto Alegre: Artmed; 2003. p. 728-73.

2. Wiebers DO, Whisnant JP, Huston J 3rd, Meissner I, Brown RD Jr, Piepgras DG, et al.; International Study of Unruptured Intracranial Aneurysms Investigators. Unruptured intracranial aneurysms: natural history, clinical outcome, and risks of surgical and endovascular treatment. Lancet. 2003;362(9378):103-10.

3. De Gans K, Nieuwkamp DJ, Rinkel GJ, Algra A. Timing of aneurysm surgery in subarachnoid hemorrhage: a systematic review of the literature. Neurosurgery. 2002;50(2):336-42.
4. Pakarinen S. Incidence, aetiology, and prognosis of primary subarachnoid haemorrhage. A study based on 589 cases diagnosed in a defined urban population during a defined period. Acta Neurol Scand. 1967;43:(Suppl 29):1-28.

5. Rinkel GJ, Djibuti M, Algra A, Van Gijn J. Prevalence and risk of rupture of intracranial aneurysms: a systematic review. Stroke. 1998;29(1):251-6.

6. Kassell NF, Drake CG. Timing of aneurysm surgery. Neurosurgery. 1982;10(4):514-9.

7. Suzuki J, Hori S, Sakurai Y. Intracranial aneurysms in the neurosurgical clinics in Japan. J Neurosurg. 1971;35(1):34-9.

8. Krex D, Schackert HK, Schackert G. Genesis of cerebral aneurysms - an update. Acta Neurochir (Wien). 2001;143(5):429-48.

9. Wardlaw JM, White PM. The detection and management of unruptured intracranial aneurysms. Brain. 2000;123(Pt 2):205-21.

10. Mhurchu CN, Anderson C, Jamrozik K, Hankey G, Dunbabin D; Australasian Cooperative Research on Subarachnoid Hemorrhage Study (ACROSS) Group. Hormonal factors and risk of aneurismal subarachnoid hemorrhage: an international population-based, case-control study. Stroke. 2001;32(3):606-12.

11. De Rooij NK, Linn FH, Van der Plas JA, Algra A, Rinkel GJ. Incidence of subarachnoid haemorrhage: a systematic review with emphasis on region, age, gender and time trends. J Neurol Neurosurg Psychiatry. 2007;78(12):1365-72.

12. Ellamushi HE, Grieve JP, Jäger HR, Kitchen ND. Risk factors for the formation of multiple intracranial aneurysms. J Neurosurg. 2001;94(5):728-32.

13. Juvela S. Risk factors for multiple intracranial aneurysms. Stroke. 2000;31(2):392-7.

14. Stehbens WE. Apoptosis and matrix vesicles in the genesis of arterial aneurysms of cerebral arteries. Stroke. 1998;29(7):1478-80.

15. Lai HP, Cheng KM, Yu SC, Au Yeung KM, Cheung YL, Chan CM, et al. Size, location, and multiplicity of ruptured intracranial aneurysms in the Hong Kong Chinese population with subarachnoid haemorrhage. Hong Kong Med J. 2009;15(4):262-6.

16. Ishibashi T, Murayama Y, Urashima M, Saguchi T, Ebara M, Arakawa $\mathrm{H}$, et al. Unruptured intracranial aneurysms: incidence of rupture and risk factors. Stroke. 2009;40(1):313-6.

17. Becker KJ. Epidemiology and clinical presentation of aneurysmal subarachnoid hemorrhage. Neurosurg Clin $\mathrm{N}$ Am. 1998;9(3):435-44.

18. Shaffrey ME, Shaffrey Cl, Lanzino G, Kassell NF. Nonoperative treatment of aneurysmal subaracnoid hemorrhage. In: Youmans JR. editor. Neurological surgery. 4th ed. Philadelphia: Saunders; 1996. p. 1264-71.

19. Kassell NF, Torner JC, Jane JA, Haley EC Jr, Adams HP. The International Cooperative Study on the Timing of Aneurysm Surgery. Part 2: Surgical results. J Neurosurg. 1990;73(1):37-47.

20. Osawa M, Hongo K, Tanaka Y, Nakamura Y, Kitazawa K, Kobayashi S. Results of direct surgery for aneurysmal subarachnoid haemorrhage: outcome of 2055 patients who underwent direct aneurysm surgery and profile of ruptured intracranial aneurysms. Acta Neurochir (Wien). 2001;143(7):655-63.

Correspondence address

Johnni Oswaldo Zamponi Junior

Rua Padre Anchieta, 2670, ap. 1506

80730-000 - Curitiba, PR, Brasil

Telefone: (044) 9973-3063

E-mail: johnni_zamponi@hotmail.com 